in vivo $34: 3005-3012(2020)$

doi:10.21873/invivo.12132

\title{
TGFBI Expression Predicts the Survival of Patients With Oropharyngeal Squamous Cell Carcinoma
}

\author{
HA-JEONG KIM ${ }^{1}$, DONGBIN AHN ${ }^{2}$, TAE-IN PARK ${ }^{3}$ and JI YUN JEONG ${ }^{3,4}$ \\ ${ }^{1}$ Department of Physiology, School of Medicine, Kyungpook National University, Daegu, Republic of Korea; \\ ${ }^{2}$ Department of Otolaryngology-Head and Neck Surgery, School of Medicine, \\ Kyungpook National University, Daegu, Republic of Korea; \\ ${ }^{3}$ Department of Pathology, School of Medicine, Kyungpook National University, Daegu, Republic of Korea; \\ ${ }^{4}$ Department of Pathology, Kyungpook National University Chilgok Hospital, Daegu, Republic of Korea
}

\begin{abstract}
Background/Aim: This study was conducted to investigate transforming growth factor beta-induced protein (TGFBI) expression and analyze the clinical and prognostic significance of TGFBI in oropharyngeal squamous cell carcinoma (OPSCC). Patients and Methods: We evaluated TGFBI expression by immunohistochemistry in 94 patients with OPSCC. For comprehensive analysis, TGFBI expression was subdivided into tumor cell score (T), stroma score (S), and the sum of two scores (TS) calculated using $H$-score. Clinicopathological features and survival outcomes were compared between groups of high expression and low expression of TGFBI in each area. Results: Overall, 12 patients (12.8\%) showed high $T$ score, and 41 patients (43.6\%) revealed high $S$ score. Although $T$ score showed no significant difference both in overall survival $(O S)(p=0.080)$ and recurrence free survival (RFS) $(p=0.272)$, high $S$ score patients had significantly worse OS $(p=0.003)$ and worse RFS ( $p=0.043)$. High TS score also showed significant association with worse $O S(p=0.011)$ and worse RFS $(p=0.021)$. High $S$ score was an independent prognostic factor predicting shorter $O S(H R=6.352,95 \% C I=1.206$ $40.050, p=0.029)$ and $R F S(H R=18.843,95 \% C I=1.030$ $344.799, p=0.048)$ in the multivariate analysis. Conclusion: High $S$ score of TGFBI was a significant predictor of poor prognosis in OPSCC. TGFBI could be a useful new predictive and prognostic biomarker in OPSCC.
\end{abstract}

This article is freely accessible online.

Correspondence to: Ji Yun Jeong, Department of Pathology, Kyungpook National University Chilgok Hospital, School of Medicine, Kyungpook National University, 807 Hoguk-ro, Buk-gu, Daegu 41404, Republic of Korea. Tel: +82 532003391, Fax: +82 532002027, e-mail: jyjeong@knu.ac.kr

Key Words: TGFBI, oropharyngeal squamous cell carcinoma.
Oropharyngeal squamous cell carcinoma (OPSCC) is a distinct subtype of head and neck cancer that occurs in the tonsil, base of tongue, and adenoids. OPSCC is known to be related traditionally to tobacco smoking and alcohol, but the incidence of human papilloma virus (HPV)-associated OPSCC has increased in the last few decades (1-3). Despite the advance in detection and therapies, the survival of OPSCC has not significantly improved in the last decades (4). OPSCC is a biologically heterogeneous disease and the patients' response to treatment is diverse. Although patients with HPV-associated OPSCC tend to be younger and respond better to treatment compared to HPV-negative OPSCC (5), the factors affecting the prognosis and response to treatment of patients with OPSCC have not been fully elucidated. To improve clinical outcomes, new biomarkers and therapeutic targets that help to identify patients who are at the highest risk for poor outcomes are urgently needed.

Transforming growth factor beta-induced protein (TGFBI), also known as $\beta$ ig-H3, is a secretory extracellular matrix protein induced by TGF- $\beta$ that mediates cell adhesion to extracellular proteins such as collagen, fibronectin, and laminin through integrin binding (6). TGFBI plays a role in morphogenesis, cell adhesion, migration, differentiation, inflammation, tumorigenesis and metastasis (7). Recently, researchers have studied the role of TGFBI in different types of tumors, with varying results. Wang et al. (8) have reported that TGFBI promotes tumor growth and is associated with poor prognosis in oral squamous cell carcinoma. Unfortunately, little is known about the exact role of TGFBI in OPSCC, and the clinical and prognostic implication remains unclear so far.

The aim of this study was to evaluate TGFBI expression and elucidate its role and clinical or prognostic implications in OPSCC. We evaluated TGFBI expression in 94 patients' tissue samples by immunohistochemistry and analyzed its prognostic value. In particular, we investigated TGFBI expression in tumor cells, stroma, and the sum of tumor cells and stroma, considering that TGFBI is an extracellular 
matrix protein. To the best of our knowledge, this is the first study to analyze TGFBI expression levels in OPSCC comprehensively, considering intensity and proportion of expression in both tumor cells and stromal components.

\section{Patients and Methods}

Patients. A series of 94 patients who had been diagnosed of OPSCC at the Kyungpook National University Hospital and Kyungpook National University Chilgok Hospital in Daegu, Korea between 2006 and 2013 were included in this study. Histologic review was performed by two experienced pathologists (J.Y.J. and T.I.P.) based on the $4^{\text {th }}$ edition of WHO classification. A retrospective review of the medical records and pathologic reports was also conducted. Pathologic staging of the tumor was re-evaluated according to the 8th edition of the Union for International Cancer Control (UICC)/American Joint Committee on Cancer (AJCC) Staging Manual. Only patients with available of medical records and sufficient tissue sections from formalin-fixed paraffin-embedded (FFPE) tissue were enrolled. The study protocol was approved by the institutional review board at Kyungpook National University Chilgok Hospital (approval no.: KNUCH 2018-08-029).

TGFBI immunohistochemistry. The expression of TGFBI was assessed using immunohistochemical staining. Immunostaining for TGFBI (clone: EPR12078(B)) (Abcam, Cambridge, UK) was conducted using standard autostaining protocols. Briefly, each $4-\mu \mathrm{m}$ tumor sections cut from FFPE was deparaffinized and pretreated for cell conditioning and antigen retrieval, and immunohistochemical staining for TGFBI was performed using Ventana BenchMark XT autoimmunostainer (Roche Ventana, Tucson, AZ, USA) according to the manufacturer's protocol. The incubation time was $30 \mathrm{~min}$.

Scoring TGFBI expression. Two pathologists (J.Y.J. and T.I.P) evaluated the score of TGFBI expression independently and unaware of the outcomes of patients. The immunohistochemical results were graded semiquantitatively using an $\mathrm{H}$-score by considering both the staining intensity (intensity score, IS) and the percentage of positive cells or area (proportion score, PS). The IS was assessed using a fourvalue scoring system with the following scale: 0 (no staining), 1 (weak), 2 (moderate), and 3 (strong). While the PS was scored as the percentage of positive cells or area $(0-100 \%)$. A final H-score was calculated by multiplying the IS (0-3) and the PS (0-100), resulting in a range of 0 to 300 . The median value of all $\mathrm{H}$ scores was chosen as the cutoff value to separate low and high expression levels of TGFBI. Disagreements, if any, were resolved through a simultaneous review on a multi-head microscope, and a consensus was achieved. The scoring of TGFBI expression was evaluated in both tumor cells (T, low $v s$. high) and stroma ( $\mathrm{S}$, low $v s$. high). The sum of $\mathrm{T}$ score and $\mathrm{S}$ score (TS, 0-2) was also calculated. Representative images of various intensities of TGFBI expression are shown in Figure 1.

Statistical analysis. We used chi-square or Fisher's exact test for comparisons of categorical variables and TGFBI expression. We defined duration of recurrence-free survival (RFS) as the interval from the time of the first surgery to the time of any relapse of disease, and duration of overall survival (OS) as the interval from the time of the first surgery to the time of death or the time of the last follow-up. The survival rates for RFS and OS were estimated using the Kaplan-Meier method, and the survival curves were compared using the log-rank test. The Cox proportional hazards regression model was used for multivariate survival analyses. The hazard ratio (HR) and 95\% confidence interval (CI) were estimated. A $p$-value of less than 0.05 was considered to indicate statistically significant differences. All statistical analyses were undertaken on SPSS version 25.0 (IBM Corporation, Armonk, NY, USA).

\section{Results}

Patients characteristics. The clinical characteristics of the 94 eligible patients are summarized in Table I. The median age was 62.5 years (range $=37-89$ years), and the proportion of men (86, $91.5 \%)$ were notably higher than women $(8,8.5 \%)$. Seventy patients $(74.5 \%)$ were current smokers or ex-smokers, and 24 patients $(25.5 \%)$ were never smokers. The most common anatomical subsite of the tumor was tonsil in 56 patients $(59.6 \%)$, and other sites included soft palate, back wall of the throat, and base of tongue in 38 patients $(40.4 \%)$. Thirteen patients $(13.8 \%)$ were stage I-II, and 81 patients $(86.2 \%)$ were stage III-IV at the time of diagnosis according to the TNM stage. Tumor grade was classified as well-differentiated in 4 patients $(4.3 \%)$, moderately differentiated in 81 patients $(86.2 \%)$, and poorly differentiated in 9 patients $(9.6 \%)$. HPV was positive in 40 patients $(42.6 \%)$ and the remaining 54 patients $(57.4 \%)$ were HPV-negative. 57 patients $(60.6 \%)$ received concurrent chemoradiotherapy (CCRT), 11 patients $(11.7 \%)$ received surgery + radiotherapy $(\mathrm{RTx}) \pm$ chemotherapy (CTx), and 26 patients (27.7\%) underwent only surgery.

TGFBI expression in OPSCC and association between PDL1 expression and clinicopathological characteristics. Ninety-four patients with OPSCC were analysed and the clinicopathological characteristics are shown in Table I. The results of TGFBI expression by immunohistochemistry are shown in Table II. The median value of TGFBI expression in tumor cells ( $\mathrm{T}$ score) was 90 (range $=0-300$ ), and the median value of TGFBI expression in stroma (S score) was 180 (range=0-300). Patients were dichotomized into high and low expression by the median H score of TGFBI expression. Overall, 12 patients (12.8\%) showed high $\mathrm{T}$ score and 41 patients $(43.6 \%)$ revealed high S score. TS score, which was the sum of $\mathrm{T}$ and $\mathrm{S}$ scores, was classified as follows: high expression (score 2) in 11 patients $(11.7 \%)$, intermediate expression (score 1) in 31 patients $(33.0 \%)$, and low expression (score 0) in 52 patients $(55.3 \%)$. The relation between clinicopathological features and TGFBI expression is also shown in Table II. No significant association was found between T, S, and TS scores of TGFBI expression and clinicopathological features of the patients (all $p>0.05$ ).

Survival analysis. The median follow-up duration was 31 months (range $=1-169$ months). T score of TGFBI expression showed no significant difference both in OS $(p=0.080$, 

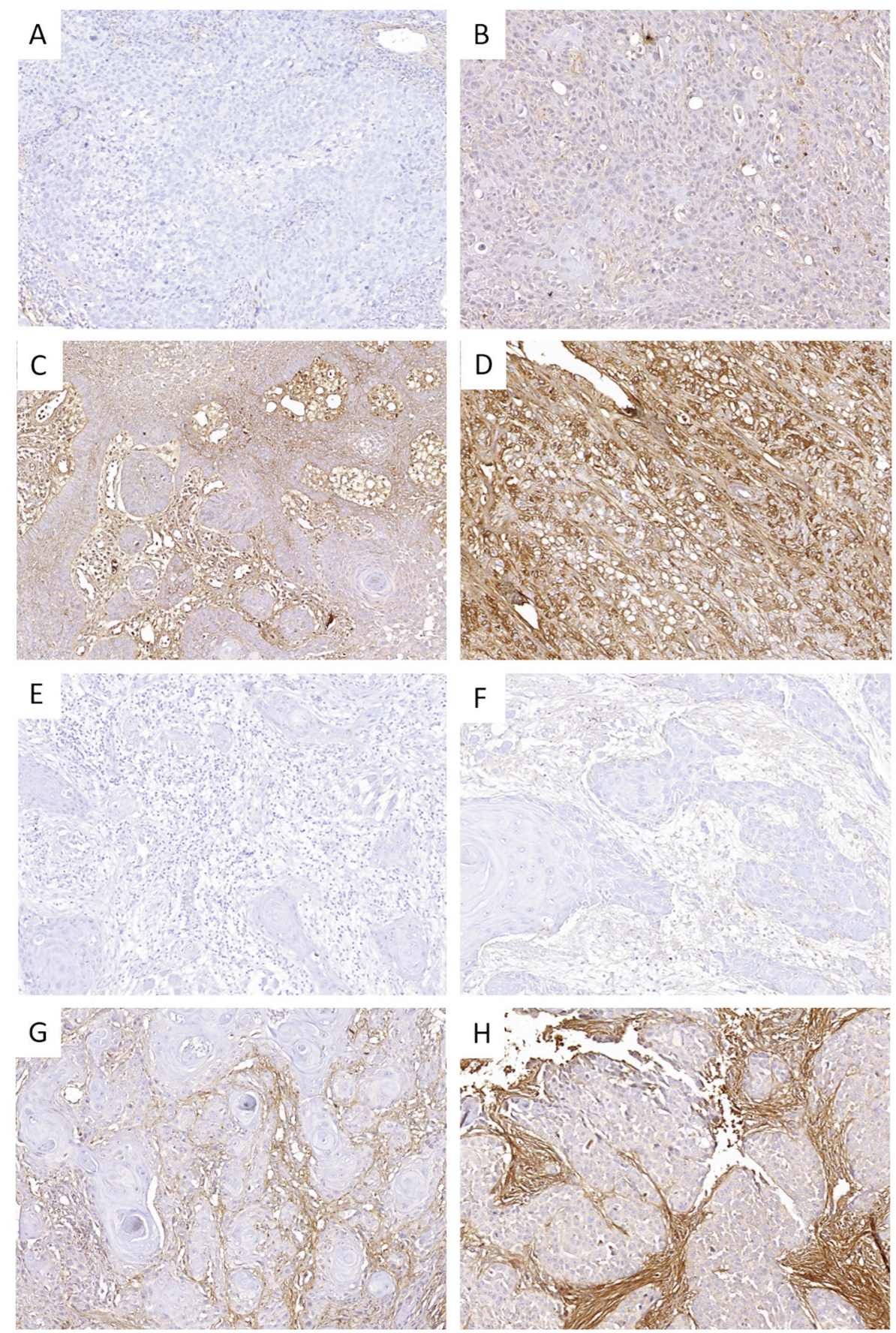

Figure 1. Representative images of TGFBI expression in oropharyngeal squamous cell carcinoma. The immunohistochemical staining shows various intensities for TGFBI in tumor cells and stroma. (A-D) The intensity scores of 0 (no staining), 1 (weak), 2 (moderate), and 3 (strong) in tumor cells are shown in order. $(E-H)$ The intensity scores of 0, 1, 2, and 3 in stroma are shown in order $(\times 100)$.

Figure 2A) and RFS ( $p=0.272$, Figure 2B). However, patients with high $\mathrm{S}$ score had significantly worse OS ( $p=0.003$, Figure 2C) and worse RFS ( $p=0.043$, Figure 2D) than those with low S score. High TS score also showed significant association with worse OS ( $p=0.011$, Figure 2E) and worse RFS ( $p=0.021$, Figure $2 F)$.

To get further insights on the value of TGFBI expression as a predictive and prognostic biomarker in OPSCC, univariate 
Table I. Clinicopathological characteristics of 94 cases of oropharyngeal cancer.

\begin{tabular}{lc}
\hline Characteristics & $\begin{array}{c}\text { No of patients } \\
\mathrm{n}=94(\%)\end{array}$ \\
\hline Age & \\
<60 years & $34(36.2)$ \\
$\geq 60$ years & $60(63.8)$ \\
Gender & \\
Male & $86(91.5)$ \\
Female & $8(8.5)$ \\
Smoking & \\
Never smoker & $24(25.5)$ \\
Current or ex-smoker & $70(74.5)$ \\
Location & \\
Tonsil & $56(59.6)$ \\
Others & $38(40.4)$ \\
T stage & \\
T1-2 & $69(73.4)$ \\
T3-4 & $25(26.6)$ \\
N stage & \\
N0 & $15(16.0)$ \\
N1-3 & $79(84.0)$ \\
AJCC stage (8th edition) & \\
I-II & $13(13.8)$ \\
III-IV & $81(86.2)$ \\
Grade & \\
Well & $4(4.3)$ \\
Moderately & $81(86.2)$ \\
Poorly & $9(9.6)$ \\
HPV status & \\
Negative & $54(57.4)$ \\
Positive & $40(42.6)$ \\
Creatment & $57(60.6)$ \\
Surgery + RTx \pm CTx & $11(11.7)$ \\
Surgery only & $26(27.7)$ \\
\hline
\end{tabular}

HPV: Human papillomavirus; CCRT: concurrent chemoradiotherapy; RTx: radiotherapy; CTx: chemotherapy.

and multivariate analyses were performed (Table III). In the multivariate analysis, high $\mathrm{S}$ score of TFGBI expression was an independent risk factor of OS (HR=6.352, 95\%CI=1.206$40.050, p=0.029$ ) along with tumor location. Regarding RFS, tumor grade was the only definite independent risk factor in multivariate analysis $(p=0.004)$. High $\mathrm{S}$ score of TGFBI expression was also thought to be a risk factor for RFS $(\mathrm{HR}=18.843,95 \% \mathrm{CI}=1.030-344.799, p=0.048)$ in multivariate analysis, although it showed a trend to be associated with shorter RFS $(\mathrm{HR}=4.586,95 \% \mathrm{CI}=0.915-22.970, p=0.064)$ in the univariate analysis.

\section{Discussion}

This study evaluated the impact of TGFBI expression on the outcome of OPSCC patients. We analyzed TGFBI expression comprehensively according to the location of the expression by subdividing TGFBI expression into tumor cells and stromal component and investigating the association between TGFBI expression and clinicopathological and prognostic features. Recently, many studies have reported on the role of TGFBI in various types of tumors. Several studies have shown that TGFBI acts as a tumor promoter in ovarian cancer (9), esophageal squamous cell carcinoma (10), renal cell carcinoma (11), melanoma (12), lung squamous cell carcinoma (13), glioblastoma (14), colon cancer (15), and lung adenocarcinoma (16). Conversely, few studies have reported that TGFBI acts as a tumor suppressor in leukemia (17), mesothelioma $(18,19)$, breast cancer $(18,20)$, and lung cancer (20). Moreover, Ween et al. (21) have reported that TGFBI could have two opposite roles in ovarian cancer by acting as either a tumor promoter or suppressor. Several studies have been conducted on the molecular or biological mechanism by which TGFBI affects tumors, and the results are also controversial. Accumulating evidence has suggested that TGFBI and TGF- $\beta$ signaling pathways play a dual role as tumor promoters or suppressors (21-23). Thapa et al. (7) have also reported that TGFBI could act as a barrier for preventing the spread of tumor cells, as well as a reservoir for cellbinding proteins and growth factors. Regarding its function as a tumor promoter, Ma et al. (24) have reported that TGFBI promotes metastasis of colon cancer by enhancing cell extravasation. On the contrary, Wen et al. (19) have reported that TGFBI acts as a tumor suppressor through the Akt/mTOR pathway. Son et al. (25) and Nam et al. (26) have suggested that TGFBI has anti-angiogenic and anti-tumor effects.

Research on the function of TGFBI in OPSCC has so far been very rare. Wang et al. (8) have investigated the role of TGFBI in oral squamous cell carcinoma and reported that TGFBI is associated with poor prognosis. Even though Wang et al. conducted a study using both cell lines and 52 patients' tissue samples, they evaluated TGFBI expression only in tumor cells. Considering that TGFBI is an extracellular matrix protein, we comprehensively analyzed the expression of TGFBI in both tumor cells and stroma and graded its expression semiquantitatively using $\mathrm{H}$-score, which combines both intensity and proportion of the expression.

In the present study, we demonstrated that high $\mathrm{S}$ score and TS score of TGFBI were significantly associated with worse outcomes in both OS ( $\mathrm{S}$ score, $p=0.003$ and TS score, $p=0.011$ ) and RFS (S score, $p=0.043$. and TS score, $p=0.021$ ). Although both S score and TS score of TGFBI were thought to have prognostic implication in the Kaplan-Meier survival curve, the $\mathrm{S}$ score defined better prognostic subgroups than TS score. We, therefore, further performed univariate and multivariate analyses including the $S$ score of TFGBI expression. Notably, high $\mathrm{S}$ score of TFGBI was an independent prognostic factor predicting shorter time to both death $(\mathrm{HR}=6.352,95 \% \mathrm{CI}=1.206-40.050, p=0.029)$ and 
Table II. Association of TGFBI expression with clinicopathological characteristics.

\begin{tabular}{|c|c|c|c|c|c|c|c|c|c|c|}
\hline \multirow[t]{2}{*}{ Characteristics } & \multicolumn{3}{|c|}{ TGFBI expression in tumor $(\mathrm{T})$} & \multicolumn{3}{|c|}{ TGFBI expression in stroma (S) } & \multicolumn{4}{|c|}{$\begin{array}{l}\text { TGFBI expression in tumor } \\
\text { and stroma (TS) }\end{array}$} \\
\hline & $\begin{array}{l}\text { High } \\
\mathrm{n}=12 \\
(12.8)\end{array}$ & $\begin{array}{c}\text { Low } \\
\mathrm{n}=82 \\
(87.2)\end{array}$ & $p$-Value & $\begin{array}{l}\text { High } \\
\mathrm{n}=41 \\
(43.6)\end{array}$ & $\begin{array}{c}\text { Low } \\
\mathrm{n}=53 \\
(56.4)\end{array}$ & $p$-Value & $\begin{array}{l}\text { High } \\
\mathrm{n}=11 \\
(11.7)\end{array}$ & $\begin{array}{c}\text { Intermediate } \\
\mathrm{n}=31 \\
(33.0)\end{array}$ & $\begin{array}{c}\text { Low } \\
\mathrm{n}=52 \\
(55.3)\end{array}$ & $p$-Value \\
\hline \multicolumn{11}{|l|}{ Age } \\
\hline$<60$ years & $3(25.0)$ & $31(37.8)$ & 0.389 & $17(41.5)$ & $17(32.1)$ & 0.348 & $3(27.3)$ & $14(45.2)$ & $17(32.7)$ & 0.420 \\
\hline$\geq 60$ years & $9(75.0)$ & $51(62.2)$ & & $24(58.5)$ & $36(67.9)$ & & $8(72.7)$ & $17(54.8)$ & $35(67.3)$ & \\
\hline \multicolumn{11}{|l|}{ Gender } \\
\hline Male & $12(100)$ & $74(90.2)$ & 0.258 & $39(95.1)$ & $47(88.7)$ & 0.267 & $11(100)$ & $29(93.5)$ & $46(88.5)$ & 0.406 \\
\hline Female & $0(0)$ & $8(9.8)$ & & $2(4.9)$ & $6(11.3)$ & & $0(0)$ & $2(6.5)$ & $6(11.5)$ & \\
\hline \multicolumn{11}{|l|}{ Smoking } \\
\hline Never smoker & $3(25.0)$ & $21(25.6)$ & 0.964 & $9(22.0)$ & $15(28.3)$ & 0.484 & $2(8.3)$ & $8(25.8)$ & $14(26.9)$ & 0.832 \\
\hline Ever smoker & $9(75.0)$ & $61(74.4)$ & & $32(78.0)$ & $38(71.7)$ & & $9(81.8)$ & $23(74.2)$ & $38(73.1)$ & \\
\hline \multicolumn{11}{|l|}{ Location } \\
\hline Tonsil & $6(50.0)$ & $50(61.0)$ & 0.469 & $25(61.0)$ & $31(58.5)$ & 0.808 & $6(54.5)$ & $19(61.3)$ & $31(59.6)$ & 0.926 \\
\hline Others & $6(50.0)$ & $32(39.0)$ & & $16(39.0)$ & $22(41.5)$ & & $5(45.5)$ & $12(38.7)$ & $21(40.4)$ & \\
\hline \multicolumn{11}{|l|}{$\mathrm{T}$ stage } \\
\hline $\mathrm{T} 1-2$ & $9(75.0)$ & $60(73.2)$ & 0.893 & $33(80.5)$ & $36(67.9)$ & 0.172 & $9(81.8)$ & $24(77.4)$ & $36(69.2)$ & 0.572 \\
\hline T3-4 & $3(25.0)$ & $22(26.8)$ & & $17(32.1)$ & $8(19.5)$ & & $2(18.2)$ & 7 (22.6) & $16(30.8)$ & \\
\hline \multicolumn{11}{|l|}{$\mathrm{N}$ stage } \\
\hline No & $2(16.7)$ & $10(83.3)$ & 0.943 & $8(19.5)$ & $7(13.2)$ & 0.408 & $1(9.1)$ & $8(25.8)$ & $6(11.5)$ & 0.184 \\
\hline $\mathrm{N} 1-3$ & $10(83.3)$ & $69(84.1)$ & & $33(80.5)$ & $46(86.8)$ & & $10(90.9)$ & $23(74.2)$ & $46(88.5)$ & \\
\hline \multicolumn{11}{|l|}{ AJCC stage ( $8^{\text {th }}$ edition $)$} \\
\hline I-II & $1(8.3)$ & $12(14.6)$ & 0.555 & $6(14.6)$ & $7(13.2)$ & 0.843 & $1(9.1)$ & $5(16.1)$ & $7(13.5)$ & 0.839 \\
\hline III-IV & $11(91.7)$ & $70(85.4)$ & & $35(85.4)$ & $46(86.8)$ & & $10(90.9)$ & $26(83.9)$ & $45(86.5)$ & \\
\hline \multicolumn{11}{|l|}{ Grade } \\
\hline Well & $0(0)$ & $4(4.9)$ & 0.517 & $2(4.9)$ & $2(3.8)$ & 0.788 & $0(0)$ & $2(6.5)$ & $2(3.8)$ & 0.926 \\
\hline Moderately & $10(83.3)$ & $71(86.6)$ & & $36(87.8)$ & 45 (84.9) & & $10(90.9)$ & $26(83.9)$ & $45(86.5)$ & \\
\hline Poorly & $2(16.7)$ & $7(8.5)$ & & $3(7.3)$ & $6(11.3)$ & & $1(9.1)$ & $3(9.7)$ & $5(9.6)$ & \\
\hline \multicolumn{11}{|l|}{ HPV status } \\
\hline Negative & $9(75.0)$ & $45(54.9)$ & 0.188 & $26(63.4)$ & $28(52.8)$ & 0.303 & $8(72.7)$ & $19(61.3)$ & $27(51.9)$ & 0.389 \\
\hline Positive & $3(25.0)$ & $37(45.1)$ & & $15(36.6)$ & $25(47.2)$ & & $3(27.3)$ & $12(38.7)$ & $25(48.1)$ & \\
\hline \multicolumn{11}{|l|}{ Treatment } \\
\hline CCRT & $8(66.7)$ & $49(59.8)$ & 0.615 & $26(63.4)$ & $31(58.5)$ & 0.841 & $7(63.6)$ & $20(64.5)$ & $30(57.7)$ & 0.766 \\
\hline Surgery $+\mathrm{RTx} \pm \mathrm{CT} x$ & $2(16.7)$ & $9(11.0)$ & & $4(9.8)$ & $7(13.2)$ & & $2(18.2)$ & $2(6.5)$ & $7(13.5)$ & \\
\hline Surgery only & $2(16.7)$ & $24(29.3)$ & & $11(26.8)$ & $15(28.3)$ & & $2(18.2)$ & $9(29.0)$ & $15(28.8)$ & \\
\hline
\end{tabular}

HPV: Human papillomavirus; CCRT: concurrent chemoradiotherapy; RTx: radiotherapy; CTx: chemotherapy.

recurrence $(\mathrm{HR}=18.843,95 \% \mathrm{CI}=1.030-344.799, p=0.048)$ in the multivariate analysis. Wang et al. (8) have reported that high TGFBI expression in oral squamous cell carcinoma was significantly associated with higher tumor stage, which implies that TGFBI was related to the development and poor prognosis of oral squamous cell carcinoma. However, Wang et al.'s study differs from the present study and has the limitations that it was conducted on oral squamous cell carcinoma, not OPSCC, which is a distinct entity, and no analysis of patients' survival was performed. Our results suggest that high expression of TGFBI in stroma contributes to poor outcomes and TGFBI could be a new prognostic biomarker in OPSCC. Further studies should investigate the molecular and biological mechanisms underpinning the aggressive behaviors and poor outcomes of patients with high TGFBI expression in OPSCC.

Our study has some limitations. First, the number of participants included in the study was relatively small since only 94 patients remained eligible for investigation when considering only those with available tissue samples. Second, because this is a retrospective study in a single center, the results could potentially have been influenced by selection bias. Further multicenter studies are needed to validate the clinical and prognostic significance of TGFBI in OPSCC. Third, we included patients who were diagnosed with OPSCC from 2006 to 2013 for the survival analysis, which means that the relatively old tissue samples could have affected the results of immunohistochemistry even though we made an effort to control the quality of FFPE 

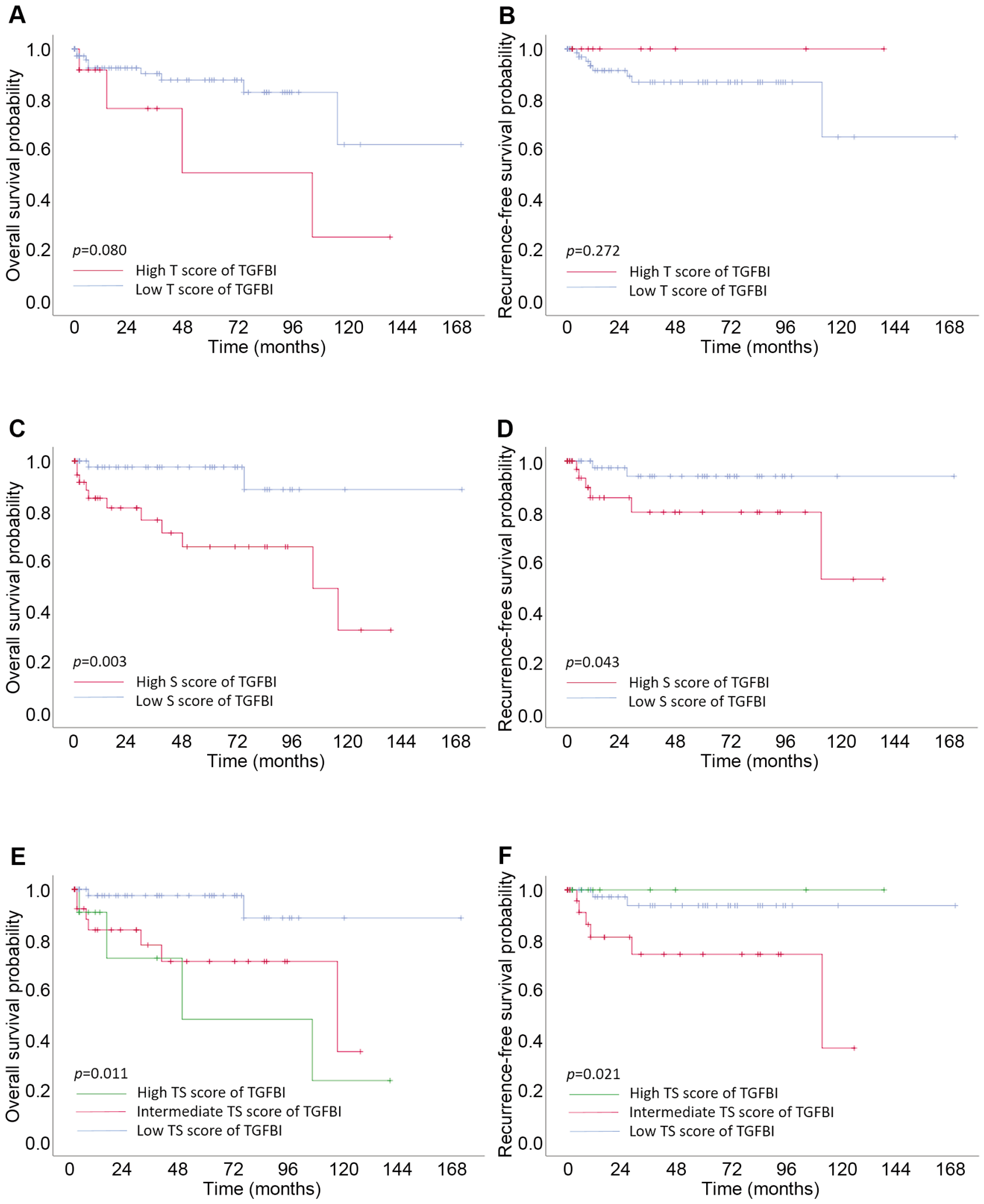

Figure 2. Kaplan-Meier survival curves for overall survival (OS) and recurrence free survival (RFS) according to TGFBI expression. Survival curves for OS (A) and RFS (B) according to T score, OS (C) and RFS (D) according to $S$ score, and OS $(E)$ and RFS $(F)$ according to TS score of TGFBI are shown. T: Expression score in tumor cells; $S$ : expression score in stroma; TS: sum of $T$ and $S$ score. p-Values by log-rank test. 
Table III. Univariate and multivariate analysis for overall survival and recurrence-free survival.

\begin{tabular}{|c|c|c|c|c|c|c|c|c|}
\hline \multirow{3}{*}{ Variables } & \multicolumn{4}{|c|}{ Overall survival } & \multicolumn{4}{|c|}{ Recurrence free survival } \\
\hline & \multicolumn{2}{|c|}{ Univariate analysis } & \multicolumn{2}{|c|}{ Multivariate analysis } & \multicolumn{2}{|c|}{ Univariate analysis } & \multicolumn{2}{|c|}{ Multivariate analysis } \\
\hline & $\begin{array}{c}\mathrm{HR} \\
(95 \% \mathrm{CI})\end{array}$ & $p$-Value & $\begin{array}{c}\mathrm{HR} \\
(95 \% \mathrm{CI})\end{array}$ & $p$-Value & $\begin{array}{c}\mathrm{HR} \\
(95 \% \mathrm{CI})\end{array}$ & $p$-Value & $\begin{array}{c}\mathrm{HR} \\
(95 \% \mathrm{CI})\end{array}$ & $p$-Value \\
\hline $\begin{array}{l}\text { Age } \\
\geq 60 \text { years } v s .<60 \text { years }\end{array}$ & $\begin{array}{c}0.611 \\
(0.201-1.858)\end{array}$ & 0.386 & & & $\begin{array}{c}0.701 \\
(0.171-2.872)\end{array}$ & 0.622 & & \\
\hline $\begin{array}{l}\text { Gender } \\
\text { Female } v s . \text { Male }\end{array}$ & $\begin{array}{c}0.043 \\
(0.000-423.234)\end{array}$ & 0.503 & & & $\begin{array}{c}0.043 \\
(0.000-2600.419)\end{array}$ & 0.575 & & \\
\hline $\begin{array}{l}\text { Smoking } \\
\quad \text { Ever smoker } v s . \text { Never smoker }\end{array}$ & $\begin{array}{c}1.404 \\
(0.385-5.122)\end{array}$ & 0.607 & & & $\begin{array}{c}1.274 \\
(0.256-6.355)\end{array}$ & 0.767 & & \\
\hline $\begin{array}{l}\text { Location } \\
\text { Other sites } v s . \text { Tonsil }\end{array}$ & $\begin{array}{c}6.365 \\
(1.737-23.329)\end{array}$ & $0.005 *$ & $\begin{array}{c}7.119 \\
(1.265-40.050)\end{array}$ & $0.026^{*}$ & $\begin{array}{c}1.144 \\
(0.271-4.839)\end{array}$ & 0.855 & & \\
\hline $\begin{array}{l}\text { T stage } \\
\text { III-IV vs. I-II }\end{array}$ & $\begin{array}{c}2.007 \\
(0.583-6.914)\end{array}$ & 0.270 & & & $\begin{array}{c}0.543 \\
(0.065-4.518)\end{array}$ & 0.572 & & \\
\hline $\begin{array}{l}\mathrm{N} \text { stage } \\
\text { I-III } v s .0\end{array}$ & $\begin{array}{c}3.111 \\
(0.403-24.000)\end{array}$ & 0.276 & & & $\begin{array}{c}1.946 \\
(0.239-15.850)\end{array}$ & 0.534 & & \\
\hline $\begin{array}{l}\text { AJCC stage ( } 8^{\text {th }} \text { edition) } \\
\text { III-IV vs. I-II }\end{array}$ & $\begin{array}{c}2.617 \\
(0.340-20.175)\end{array}$ & 0.356 & & & $\begin{array}{c}1.605 \\
(0.197-13.068)\end{array}$ & 0.658 & & \\
\hline Tumor grade & 0.386 & & & & 0.109 & & 0.014 & \\
\hline Moderately vs. Well & $(0.081-1.853)$ & 0.235 & & & $(0.025-0.481)$ & $0.003^{*}$ & $(0.001-0.247)$ & $0.004 *$ \\
\hline Poorly $v s$. Well & $\begin{array}{c}0.330 \\
(0.028-3.910)\end{array}$ & 0.380 & & & $\begin{array}{c}0.000 \\
(0.000-0.000)\end{array}$ & 0.982 & & \\
\hline $\begin{array}{l}\text { HPV } \\
\quad \text { Positive } v s . \text { Negative }\end{array}$ & $\begin{array}{c}0.614 \\
(0.200-1.890)\end{array}$ & 0.395 & & & $\begin{array}{c}0.927 \\
(0.231-3.726)\end{array}$ & 0.915 & & \\
\hline $\begin{array}{l}\text { TGFBI } \\
\text { S High } v s \text {. Low expression }\end{array}$ & $\begin{array}{c}7.261 \\
(1.597-33.015)\end{array}$ & $0.010 *$ & $\begin{array}{c}6.352 \\
(1.206-33.447)\end{array}$ & $0.029^{*}$ & $\begin{array}{c}4.586 \\
(0.915-22.970)\end{array}$ & 0.064 & $\begin{array}{c}18.843 \\
(1.030-344.799)\end{array}$ & $0.048^{*}$ \\
\hline $\begin{array}{l}\text { Treatment } \\
\text { Surgery + RTx } \pm \text { CTx vs. CCRT } \\
\text { Surgery only vs. CCRT }\end{array}$ & $\begin{array}{c}0.633 \\
(0.080-5.012) \\
0.617 \\
(0.124-3.072)\end{array}$ & 0.665 & & & $\begin{array}{c}2.395 \\
(0.454-12.641) \\
0.632 \\
(0.062-6.467)\end{array}$ & $\begin{array}{l}0.304 \\
0.699\end{array}$ & & \\
\hline
\end{tabular}

HR: Hazard ratio; CI: confidence interval; HPV: human papillomavirus; CCRT: concurrent chemoradiotherapy; RTx: radiotherapy; CTx: chemotherapy. HRs, $95 \%$ CIs and their corresponding $p$-values were calculated using Cox proportional hazard models. *Statistically significant, $p<0.05$.

samples. Fourth, our study was conducted using only clinical patients' samples, which means further studies for defining the biological mechanisms are needed.

In conclusion, high $\mathrm{S}$ score of TGFBI was significantly associated with poor outcomes in OPSCC. Our results suggest that TGFBI could be a useful predictive and prognostic biomarker in OPSS patients. Further large-scale studies and investigations of the underlying biological mechanisms for the poor outcome are necessary to establish the definite role of TGFBI in OPSCC.

\section{Conflicts of Interest}

All Authors declare no conflicts of interest regarding this study.

\section{Authors' Contributions}

Conceived and designed the study: J.Y.J. Acquired clinical data: D.A. Analyzed and interpreted the data: J.Y.J. and T.I.P. Wrote the main manuscript text: H.J.K. Revised the manuscript: T.I.P. and D.A. Supervised the study: J.Y.J. Authors made substantial contributions to the design of the study, acquisition of data, analysis and interpretation of the data, writing the manuscript, and revising the manuscript. All Authors approved the final version of the manuscript.

\section{References}

1 Schwartz SM, Daling JR, Doody DR, Wipf GC, Carter JJ, Madeleine MM, Mao EJ, Fitzgibbons ED, Huang S, Beckmann AM, McDougall JK and Galloway DA: Oral cancer risk in relation to sexual history and evidence of human papillomavirus infection. J Natl Cancer Inst 90(21): 1626-1636, 1998. PMID: 9811312. DOI: $10.1093 /$ jnci/90.21.1626

2 Steinberg BM and DiLorenzo TP: A possible role for human papillomaviruses in head and neck cancer. Cancer Metastasis Rev 15(1): 91-112, 1996. PMID: 8842481. DOI: 10.1007/BF00049489

3 Ritchie JM, Smith EM, Summersgill KF, Hoffman HT, Wang D, Klussmann JP, Turek LP and Haugen TH: Human papillomavirus infection as a prognostic factor in carcinomas of the oral cavity 
and oropharynx. Int J Cancer 104(3): 336-344, 2003. PMID: 12569557. DOI: $10.1002 /$ ijc. 10960

4 Sahu N and Grandis JR: New advances in molecular approaches to head and neck squamous cell carcinoma. Anticancer Drugs 22(7): 656-664, 2011. PMID: 21178766. DOI: 10.1097/ CAD.0b013e32834249ba

5 Richards L: Human papillomavirus-a powerful predictor of survival in patients with oropharyngeal cancer. Nat Rev Clin Oncol 7(9): 481, 2010. PMID: 20824898. DOI: 10.1038/nrclinonc.2010.124

6 Kim JE, Kim SJ, Lee BH, Park RW, Kim KS and Kim IS: Identification of motifs for cell adhesion within the repeated domains of transforming growth factor-beta-induced gene, beta ig-h3. J Biol Chem 275(40): 30907-30915, 2000. PMID: 10906123. DOI: DOI 10.1074/jbc.M002752200

7 Thapa N, Lee BH and Kim IS: TGFBIP/beta ig-h3 protein: A versatile matrix molecule induced by tgf-beta. Int J Biochem Cell Biol 39(12): 2183-2194, 2007. PMID: 17659994. DOI: 10.1016/j.biocel.2007.06.004

8 Wang BJ, Chi KP, Shen RL, Zheng SW, Guo Y, Li JF, Fei J and He Y: Tgfbi promotes tumor growth and is associated with poor prognosis in oral squamous cell carcinoma. J Cancer 10(20): 4902-4912, 2019. PMID: 31598162. DOI: 10.7150/jca.29958

9 Karlan BY, Dering J, Walsh C, Orsulic S, Lester J, Anderson LA, Ginther CL, Fejzo M and Slamon D: POSTN/TGFBIassociated stromal signature predicts poor prognosis in serous epithelial ovarian cancer. Gynecol Oncol 132(2): 334-342, 2014. PMID: 24368280. DOI: 10.1016/j.ygyno.2013.12.021

10 Ozawa D, Yokobori T, Sohda M, Sakai M, Hara K, Honjo H, Kato H, Miyazaki $\mathrm{T}$ and Kuwano H: TGFBI expression in cancer stromal cells is associated with poor prognosis and hematogenous recurrence in esophageal squamous cell carcinoma. Ann Surg Oncol 23(1): 282-289, 2016. PMID: 25448803. DOI: $10.1245 / \mathrm{s} 10434-014-4259-4$

11 Lebdai S, Verhoest G, Parikh H, Jacquet SF, Bensalah K, Chautard D, Leclercq NR, Azzouzi AR and Bigot P: Identification and validation of tgfbi as a promising prognosis marker of clear cell renal cell carcinoma. Urol Oncol 33(2), 2015. PMID: 25035170. DOI: 10.1016/j.urolonc.2014.06.005

12 Lauden L, Siewiera J, Boukouaci W, Ramgolam K, Mourah S, Lebbe C, Charron D, Aoudjit F, Jabrane-Ferrat N and Al-Daccak R: TGF-beta-induced (tgfbi) protein in melanoma: A signature of high metastatic potential. J Invest Dermatol 134(6): 16751685, 2014. PMID: 24499734. DOI: 10.1038/jid.2014.20

13 Pajares MJ, Agorreta J, Salvo E, Behrens C, Wistuba II, Montuenga LM, Pio R and Rouzaut A: TGFBI expression is an independent predictor of survival in adjuvant-treated lung squamous cell carcinoma patients. Br J Cancer 110(6): 15451551, 2014. PMID: 24481402. DOI: $10.1038 /$ bjc.2014.33

14 Lin BY, Madan A, Yoon JG, Fang XF, Yan XW, Kim TK, Hwang D, Hood L and Foltz G: Massively parallel signature sequencing and bioinformatics analysis identifies up-regulation of TGFBI and SOX4 in human glioblastoma. Plos One 5(4), 2010. PMID: 20419098. DOI: 10.1371/journal.pone.0010210

15 Zhu J, Chen XJ, Liao ZC, He C and Hu XT: TGFBI protein high expression predicts poor prognosis in colorectal cancer patients. Int J Clin Exp Pathol 8(1): 702-710, 2015. PMID: 25755764.
16 Seok Y, Lee WK, Park JY and Kim DS: Tgfbi promoter methylation is associated with poor prognosis in lung adenocarcinoma patients. Mol Cells 42(2): 161-165, 2019. PMID: 30726660. DOI: 10.14348/molcells.2018.0322

17 Fang HB, Liu J, Guo D, Liu PX and Zhao YL: Epigenetic regulation of putative tumor suppressor TGFBI in human leukemias. Chin Med J 127(9): 1645-1650, 2014. PMID: 24791868.

18 Li BY, Wen GY, Zhao YL, Tong J and Hei TK: The role of TGFBI in mesothelioma and breast cancer: Association with tumor suppression. BMC Cancer 12, 2012. PMID: 22695319. DOI: $10.1186 / 1471-2407-12-239$

19 Wen GY, Hong M, Li BY, Liao WP, Cheng SK, Hu BR, Calaf GM, Lu P, Partridge MA, Tong J and Hei TK: Transforming growth factor-beta-induced protein (TGFBI) suppresses mesothelioma progression through the akt/mtor pathway. Int $\mathbf{J}$ Oncol 39(4): 1001-1009, 2011. PMID: 21701776. DOI: 10.3892/ijo.2011.1097

20 Wen GY, Partridge MA, Li BY, Hong M, Liao WP, Cheng SK, Zhao YL, Calaf GM, Liu T, Zhou J, Zhang ZL and Hei TK: TGFBI expression reduces in vitro and in vivo metastatic potential of lung and breast tumor cells. Cancer Lett 308(1): 2332, 2011. PMID: 21561707. DOI: 10.1016/j.canlet.2011.04.010

21 Ween MP, Oehler MK and Ricciardelli C: Transforming growth factor-beta-induced protein (TGFBI)/(betaig-h3): A matrix protein with dual functions in ovarian cancer. Int J Mol Sci 13(8): 1046110477, 2012. PMID: 22949874. DOI: 10.3390/ijms 130810461

22 Massague J: TGF beta signalling in context. Nat Rev Mol Cell Biol 13(10): 616-630, 2012. PMID: 22992590. DOI: 10.1038/nrm3434

23 Yokobori $\mathrm{T}$ and Nishiyama M: TGF-beta signaling in gastrointestinal cancers: Progress in basic and clinical research. J Clin Med 6(1), 2017. PMID: 28106769. DOI: ARTN 11. $10.3390 / \mathrm{jcm} 6010011$

24 Ma C, Rong Y, Radiloff DR, Datto MB, Centeno B, Bao S, Cheng AW, Lin F, Jiang S, Yeatman TJ and Wang XF: Extracellular matrix protein betaig-h3/TGFBI promotes metastasis of colon cancer by enhancing cell extravasation. Genes Dev 22(3): 308-321, 2008. PMID: 18245446. DOI: $10.1101 / \mathrm{gad} .1632008$

25 Son HN, Nam JO, Kim S and Kim IS: Multiple fas 1 domains and the rgd motif of TGFBI act cooperatively to bind alpha $\mathrm{v}$ beta 3 integrin, leading to anti-angiogenic and anti-tumor effects. Biochim Biophys Acta 1833(10): 2378-2388, 2013. PMID: 23792174. DOI: 10.1016/j.bbamcr.2013.06.012

26 Nam JO, Jung MY, Thapa N, Lee BH, Park RW and Kim IS: Tcam, a fastatin-fiii 9-10 fusion protein, potently enhances antiangiogenic and anti-tumor activity via alphavbeta3 and alpha5beta1 integrins. Exp Mol Med 40(2): 196-207, 2008. PMID: 18446058. DOI: 10.3858/emm.2008.40.2.196

Received June 22, 2020

Revised July 6, 2020

Accepted July 8, 2020 